\title{
Has the time come for de-escalation in the management of oropharyngeal carcinoma?
}

\author{
Jana Durkovaa ${ }^{a}$ Martin Boldis ${ }^{b}$, Slavomira Kovacovac
}

\begin{abstract}
Over the course of the last two decades, there has been a decrease in the incidence of head and neck cancers thanks to a decreasing prevalence of smoking. However, a new risk factor has been coming to the fore: human papillomavirus infection (HPV). HPV-positive oropharyngeal squamous cell carcinoma (HPV+OPC) is more sensitive to chemotherapy and radiotherapy, which translates to a much better prognosis with conventional treatment protocols than tumours that are HPV-negative. Traditional therapeutic interventions are associated with substantial morbidity and have a great impact on patient quality of life. The main focus is on identifying an ideal group of HPV-positive patients who could receive de-intensification treatment regimens aimed at avoiding the late toxicity of treatment. Various strategies are considered, such as reduction in radiotherapy dose following induction chemotherapy, radiotherapy alone, minimally invasive surgical techniques, and substituting platinum-based chemotherapy. The first generation of de-escalation randomised phase III trials have now been published. The following review summarizes the current knowledge and treatment of oropharyngeal carcinoma.
\end{abstract}

Key words: oropharyngeal carcinoma, human papillomavirus (HPV), treatment de-escalation/de-intensification, prognostic and predictive markers

Received: October 31, 2019; Revised: November 18, 2019; Accepted: November 26, 2019; Available online: December 3, 2019 https://doi.org/10.5507/bp.2019.059

(c) 2019 The Authors. This is an open access article licensed under the Creative Commons Attribution License

(https://creativecommons.org/licenses/by/4.0/).

${ }^{a}$ Department of Radiotherapy and Clinical Oncology, Faculty Hospital Nitra, Slovak Republic ${ }^{b}$ Clinic of Otorhinolaryngology, Faculty Hospital Nitra, Slovak Republic

'Neurological Clinic, Faculty Hospital Nitra, Slovak Republic

Corresponding author: Jana Durkova, e-mail:durkojana@gmail.com

\section{INTRODUCTION}

Head and neck cancers represent the sixth most common malignancy worldwide. There are approximately 630,000 new patients diagnosed annually, with 350,000 succumbing to the disease ${ }^{1}$. HPV+OPC incidence has steadily increased in many parts of the world during recent decades ${ }^{2,3}$. While in the past, head and neck cancer was diagnosed predominantly in older people with a habit of excessive alcohol consumption and smoking, nowadays we are seeing an increasing incidence of oropharyngeal carcinomas in patients who are younger, in good health, with good social backgrounds and social status, who often do not present with risk factors such as smoking or alcohol abuse ${ }^{3,4}$. The substantial increase in incidence of $\mathrm{HPV}+\mathrm{OPC}$ has been attributed to a probable increase in HPV infection ${ }^{4}$. This increase could be due to changes in sexual practices (lifetime number of oral sexual partners) within the affected population ${ }^{5}$. HPV-positive tumours are diagnosed preferentially in the oropharyngeal region, especially in the tonsil and tongue base, and they represent a new subgroup of tumours with various biological, epidemiologic and molecular characteristics (Table 1) (ref., ${ }^{4,6,7}$ ).

Patients suffering from HPV-associated carcinoma respond better to treatment, and have a lower risk of locoregional recurrence, as well as lower incidence of secondary primary carcinoma ${ }^{8,9}$. HPV-positive tumours are charac- terised by high-expression $\mathrm{p} 16\left(\right.$ ref. $^{10}$ ), a protein that is involved in head and neck cancer pathogenesis. HPV status is considered the most important prognostic indicator in head and neck cancer, reflected by the inclusion of p16 status in the eighth edition of the American Joint Committee on Cancer Staging System (Table 2) (ref., ${ }^{4,10,11}$ ). However, there is currently no evidence that the new staging of $\mathrm{HPV}+\mathrm{OPC}$ should drive clinical decision-making. There is global consensus about the need for treatment de-escalation (reduction of toxicity while preserving antitumour efficacy) for patients with HPV+OPC (ref. ${ }^{12,13}$ ). Since surgery coupled with concomitant chemoradiation (CRT) is the cornerstone of a curative treatment in head and neck cancers, the current clinical studies focus primarily on minimally-invasive surgical procedures, administered radiation dose reduction, and nephrotoxic cisplatin dose substitution/reduction.

\section{Chemotherapy de-intensification, replacement of cisplatin.}

Cetuximab is a monoclonal antibody that binds to the epidermal growth factor receptor (EGFR) (ref. $\left.{ }^{14}\right)$. EGFR is involved in the activation of several oncogenic pathways and is overexpressed in up to $90 \%$ of patients with head and neck cancer ${ }^{14}$. EGFR expression is a strong, independent, prognostic factor in squamous cell carcinomas of the head and neck (HNSCC). High EGFR ex- 
Table 1. Characteristics of patients with HPV-positive and negative oropharyngeal carcinoma.

\begin{tabular}{lll}
\hline & HPV-negative OPC & HPV-positive OPC \\
\hline Risk factors & Alcohol, tobacco use & Sexual behaviour, HPV infection, immunosuppression \\
Incident trends & Decreasing & Increasing \\
Age & Older men & More likely to be younger (aged < 60 years) men \\
Tumour location & All sites & Base of the tongue, tonsil \\
Stage & Variable & Advanced stages (small T, massive N involvement) \\
Radiological image & Any & Cystic nodal involvement \\
Histopathological features & Keratinising & Baseloid, Non-keratinising \\
Tumour differentiation & Any & Undifferentiated \\
Outcomes & Worse OS and PFS & Better OS and PFS \\
Locoregional recurrence & Higher & Lower \\
Metastatic dissemination & Often within 2 years, lung & Later ( > 2 years), unusual locations other than just lung \\
& & (i.e., skin, liver, brain) \\
Second primary tumours & Common & Less common \\
\hline
\end{tabular}

OPC, oropharyngeal carcinoma; HPV, human papillomavirus; OS, overall survival; PFS, progression free survival; N, lymph node; T, tumor

Table 2. New TNM staging system classification for HPV-related OPSCC patients 8th edition, developed by The International Collaboration on Oropharyngeal Cancer Network for Staging (ICON-S).

\begin{tabular}{|c|c|c|}
\hline Characteristics & $7^{\text {th }}$ edition TNM & $8^{\text {th }}$ edition TNM \\
\hline Stage classifications & $\begin{array}{l}\text { Stage I (T1N0) } \\
\text { Stage II (T2N0) } \\
\text { Stage III (T3N0 or T1-T3N1) } \\
\text { Stage IVa (T4aN0-1 or T1-T4aN2) } \\
\text { Stage IVb (T4b or T1-T4bN3) } \\
\text { Stage IVc (M1) }\end{array}$ & $\begin{array}{l}\text { Stage I (T1-T2N0-N1) } \\
\text { Stage II (T1-T2N2 or T3N0-N2) } \\
\text { Stage III (T4 or N3) } \\
\text { Stage IV (M1) }\end{array}$ \\
\hline $\begin{array}{l}\text { Main N (lymph node) } \\
\text { differences }\end{array}$ & $\begin{array}{l}\mathrm{N} 1: \text { metastasis in a single ipsilateral lymph } \\
\text { nodes, }<3 \mathrm{~cm} \\
\mathrm{~N} 2 \mathrm{a}: \text { metastasis in a single ipsilateral lymph } \\
\text { node }>3 \mathrm{~cm} \text { but }<6 \mathrm{~cm} \text {. } \\
\mathrm{N} 2 \mathrm{~b}: \text { metastasis in multiple ipsilateral lymph } \\
\text { nodes, }<6 \mathrm{~cm} \\
\mathrm{~N} 2 \mathrm{c} \text { : metastasis in bilateral or contralateral } \\
\text { lymph nodes, }<6 \mathrm{~cm}\end{array}$ & $\begin{array}{l}\text { N1: ipsilateral metastasis in lymph node }(\mathrm{s}), \\
<6 \mathrm{~cm} \\
\mathrm{~N} 2: \text { bilateral or contralateral metastasis in lymph } \\
\operatorname{node}(\mathrm{s}),<6 \mathrm{~cm}^{\mathrm{a}}\end{array}$ \\
\hline Main T (tumor) differences & $\begin{array}{l}\text { T4a: tumor invades the larynx, extrinsic } \\
\text { muscle of tongue, medial pterygoid, hard } \\
\text { palate or mandible } \\
\text { T4b: tumor invades lateral pterygoid muscle, } \\
\text { pterygoid plates, lateral nasopharynx, skull } \\
\text { base or encases carotid artery }\end{array}$ & $\begin{array}{l}\text { T4: tumor invades any of the following: larynx, } \\
\text { deep/extrinsic muscle of tongue, medial ptery- } \\
\text { goid, hard palate, mandible, lateral pterygoid } \\
\text { muscle, pterygoid plates, lateral nasopharynx, } \\
\text { skull base or encases carotid artery }{ }^{\mathrm{b}}\end{array}$ \\
\hline
\end{tabular}

HPV, human papillomavirus; ICON-S, The International Collaboration on Oropharyngeal cancer Network for Staging; M, metastasis;

$\mathrm{N}$, lymph node; OPSCC, oropharyngeal squamous cell carcinoma; $\mathrm{T}$, tumor; OS, overall survival

${ }^{a}$ Because 5-years OS was similar among N1, N2a and N2b, they re-termed the N categories.

${ }^{\mathrm{b}}$ Because 5 -years OS was similar among T4a and T4b, they were no longer subdivided and it was re-termed as T4

pression is associated with poorer clinical outcomes in HPV-negative patients with HNSCC ( ref. $^{15}$ ). HPV+OPCs were less likely to overexpress EGFR (ref. ${ }^{15,16}$ ). The use of cetuximab in HPV-positive patients is based on the results of the Bonner et al. study, which demonstrated the effectiveness of cetuximab in locally advanced HNSCC. In this trial, bioradiotherapy with cetuximab was shown to significantly improve overall survival (OS) compared with radiotherapy (RT) alone (median 49.0 months vs 29.3 months) in patients with HNSCC (ref. ${ }^{17}$ ). In secondary analysis the impact was evaluated of p16 protein and HPV DNA status on outcomes in patients with OPC.
These data suggest that regardless of p16 status, patient outcomes were improved by the addition of cetuximab to RT compared with RT alone. Therefore, although p16 status is a strong prognostic biomarker, it does not seem to predict the effect of cetuximab. This subgroup analysis suggested that a more pronounced benefit from cetuximab may be exhibited in the p16-positive population compared with the p16-negative population; however, no significant interaction between treatment groups and p16 status could be shown ${ }^{18}$. There were several limitations to this study. This was a retrospective analysis of HPV status in a previously unselected population, and the sample size of 
the p16-positive subgroup was small, precluding statistical analysis. The medical community has long been awaiting the results of the RTOG 1016 and De-ESCALATE, phase III studies, which examined the effectiveness of replacing cisplatin with cetuximab in HPV+OPC. RTOG 1016 was a randomised, multicentre, non-inferiority trial in patients with locally advanced HPV+OPC. 987 patients were enrolled, of whom 849 received accelerated intensity-modulated RT ( 70 Gy in 35 fractions) with either concurrent cetuximab (loading dose followed by cetuximab weekly) or high-dose cisplatin. The goal of the study was to determine if substitution of cisplatin with cetuximab would result in a comparable 5-year OS. After a median follow-up of 4.5 years, RT plus cetuximab did not meet the non-inferiority criteria for OS (77.9\% vs $84.6 \%$ ) and progression free survival (PFS) $(67.3 \%$ vs $78.4 \%)$ (ref. $\left.{ }^{19}\right)$. Estimated 5-year rates of local-regional failure were also better in the cisplatin arm $(9.9 \%$ vs $17.3 \%)$ (ref. $\left.{ }^{19}\right)$, and there was no significant difference in distant metastasis between the cetuximab and cisplatin arms. Proportions of moderate to severe toxicity (acute and late) were similar between groups ${ }^{19}$. The international, randomised controlled trial De-ESCALATE has a similar design. 334 patients with low-risk (non-smoker or lifetime smoker with <10 packyear smoking history) HPV+OPC were randomly assigned to receive either high-dose cisplatin or cetuximab (loading dose followed by seven weekly infusions) in addition to a standardised RT (70 Gy in 35 fractions). The primary outcome of this study was overall severe toxicity events (grade 3-5), and secondary outcomes included OS, time to recurrence, quality of life, and swallowing outcomes. Results of this trial show that, not only did cetuximab result in similar rates of severe and all-grade toxicity to cisplatin, but it importantly resulted in poorer 2-year OS (97.5\% vs $89.4 \%$ ) and higher rates of locoregional recurrence $(6.0 \%$ vs $16.1 \%)$ (ref. $\left.{ }^{20}\right)$ and distant metastases than did standard cisplatin therapy. The spectrum of toxicity varied substantially between the two groups, with skin toxicity and infusion reactions more common in the cetuximab group and gastrointestinal and labyrinthine symptoms predominating in the cisplatin group. Equally, there was no difference between the groups in quality of life or swallowing outcomes ${ }^{20}$. Results of both studies further support cisplatin as the radiosensitiser as the standard of care in all eligible patients with head and neck cancer even for low-risk HPV-positive patients. The purpose of the Trans-Tasman Radiation Oncology Group 12.01, phase III trial is to compare the treatment-related side effects (both acute and longer term) between the cisplatin and cetuximab regimens. Both treatments would be given weekly for the duration of the radiotherapy (70 Gy in 35 fractions). Preliminary results are anticipated soon. These findings will help determine the optimal treatment for patients with $\mathrm{HPV}+\mathrm{OPC}$ (ref. ${ }^{21}$ ).

Immunotherapy. Over the past few years immune checkpoint inhibitors have changed treatment paradigms in many malignancies, and are currently under investigation in head and neck cancer as well. Nivolumab and pembrolizumab (both anti-PD-1 antibody) are recommended as category 1 in recurrent and/or metastatic head and neck cancer (non-nasopharyngeal cancer) if the disease progresses during or after platinum-based chemotherapy $^{22}$. Based on the phase III CheckMate 141 study, the OS benefit of nivolumab was independent of p16 status, although the benefit was more pronounced in the p16-positive OPC ( ref. $^{23}$ ). The Keynote-012 study, which investigated the efficacy of pembrolizumab, also observed a higher response in patients with recurrent or metastatic HPV+OPC ( ref. $^{24}$ ). The role of RT and the synergy with immunotherapy as adjuvant or concomitant treatment for advanced $\mathrm{HPV}+\mathrm{OPC}$ is still under investigation. $\mathrm{HPV}+\mathrm{OPC}$ are believed to benefit more from immunotherapy than HPV-negative disease, because HPVpositive tumours express viral antigens and because of tumour location in lymphoid tissues (tonsils or base of tongue). Viral antigens can be recognised as foreign by the patient's immune system, leading to immune recognition and activation. Tumour location of $\mathrm{HPV}+\mathrm{OPC}$ leads to the presence of a higher level of CD8+ and PD-1 tumour infiltrating lymphocytes, which may play a crucial role in the better response of HPV+OPC to immunotherapy ${ }^{25,26}$.

\section{Reduction of total radiation dose}

Morbidity caused by RT is dose-dependent. The degree of dysphagia, stricture formation, feeding tube dependence and aspiration can be reduced if the total radiation dose to the pharyngeal constrictors is limited to 52-55 Gy, and increases substantially if more than $50 \%$ of the superior and $30 \%$ of the middle pharyngeal constrictors have been subjected to 70 Gy or more ${ }^{27-29}$. Moreover, HPV-positive status is associated with an increased risk of stroke or transient ischemic attack following RT for head and neck cancer ${ }^{30}$. Therefore, reducing the dose to limit swallowing disorders is an interesting approach to improving the quality of life. Taking into account the excellent prognosis of HPV-positive patients and the fact that these tumours are assumed to be more radiosensitive, several investigators have hypothesised that this strategy is possible. Different approaches have been proposed. Several trials are based on induction chemotherapy to select good responders that could benefit from a reduction in radiation dose. The other de-intensification treatment strategy currently subject to clinical research is overall radiation dose reduction (Table 3 ) (ref. ${ }^{6,12,13}$ ).

ECOG 1308 was the first phase II trial evaluated as to whether complete clinical response (cCR) to induction chemotherapy (IC) could select patients with HPV+OPC for reduced radiation dose (from 69 to $54 \mathrm{~Gy}$ ) as a means of sparing late sequelae. In this study IC (Cisplatin, Cetuximab, and Paclitaxel) was used as a biomarker of responsiveness, and the demonstrated radiation dose could be reduced in a subset of patients with $\mathrm{HPV}+\mathrm{OPC}$ showing tumour sensitivity to chemotherapy. Fifty-six patients $(70 \%)$ achieved a primary-site cCR to IC and 51 patients continued to receive cetuximab with IMRT 54 Gy. After a median follow-up of 35.4 months, 2-year PFS and OS rates were $80 \%$ and $94 \%$ respectively, for patients with primary site cCR treated with 54 Gy of radiation) $\left(\right.$ ref. $\left.^{31}\right)$. Responders to IC who received reduced-dose radiation appeared to have significantly less late swallowing 
Table 3. Selection of treatment de-escalation trials for HPV-driven oropharyngeal cancer.

\begin{tabular}{|c|c|c|c|c|}
\hline Name study & Phase & $\mathrm{n}$ & Population & Design \\
\hline \multicolumn{5}{|c|}{ Substitution of cisplatin by cetuximab } \\
\hline $\begin{array}{l}\text { RTOG } 1016 \\
\text { NCT01302834 }\end{array}$ & III & 987 & Stage III-IV & RT (70 Gy) with high-dose Cisplatin or weekly Cetuximab \\
\hline $\begin{array}{l}\text { De Escalate } \\
\text { NCT01874171 }\end{array}$ & III & 304 & Stage III-IVa & RT (70 Gy) with high-dose Cisplatin or weekly Cetuximab \\
\hline NCT01855451 & III & 200 & Stage III-IV & RT (70 Gy) with weekly Cetuximab or weekly Cisplatin \\
\hline
\end{tabular}

Induction chemotherapy followed by lower radiation dose in good responders

ECOG $1308 \quad$ II $\quad 80$ Stage III-IV Paclitaxel, Cisplatin and Cetuximab followed by low (54 Gy) or

NCT01084083 standard dose IMRT with Cetuximab

Quarterback III 365 Stage III-IV 3 Cycles TPF followed by low (56 Gy) or standard dose (70 Gy) IMRT

NCT01706939 with weekly cetuximab + carboplatin or carboplatin only, depending on the response to IC

Induction chemotherapy followed by reduced (chemo)radiation dose and volume in good responders

Optima II 62 Stage III-IV Patients (pts) are classified as low-risk (T3, N2b, $10 \leq$ PYH) or high-risk NCT02161562 (T4 or N2c or >10 PYH)

All pts receive 3 cycles of carboplatin and nab-paclitaxel and dose/volume adapted RT

1) Low-risk pts with $50 \%$ response received low-dose RT alone to $50 \mathrm{~Gy}$.

2) Low-risk pts with $30-50 \%$ response OR high-risk pts with 50\% response received low-dose CRT to $45 \mathrm{~Gy}$.

3) All other pts, i.e. poor responders, receive regular-dose CRT.

All pts also received de-escalated RT volumes limited to the first echelon of uninvolved nodes. CRT consisted of paclitaxel, 5-FU, hydroxyurea, and 1.5 Gy twice daily RT every other week.

De-intensification of surgery/adjuvant therapy

\begin{tabular}{|c|c|c|c|}
\hline $\begin{array}{l}\text { ECOG } 3311 \\
\text { NCT01898494 }\end{array}$ & II & 377 & Stage III-IVb \\
\hline $\begin{array}{l}\text { PATHOS trial } \\
\text { NCT02215265 }\end{array}$ & II/III & 242 & $\begin{array}{l}\text { Stage T1-3, } \\
\text { N0-2b }\end{array}$ \\
\hline $\begin{array}{l}\text { ADEPT trial } \\
\text { NCT01687413 }\end{array}$ & III & 500 & $\begin{array}{l}\text { Stage T1-4a, } \\
\text { pN positive } \\
\text { with ECE }\end{array}$ \\
\hline
\end{tabular}

TORS then risk adapted post-operative treatment (observation/50 vs 60/66 Gy with weekly platinum)

TORS then re-adapted post-operative treatment (observation/50 vs 60/66 Gy with or without weekly platinum)

Post-operative adjuvant RT 60 Gy with or without weekly platinum with ECE

ADEPT, Post Operative Adjuvant Therapy De-intensification Trial for Human Papillomavirus-related P16+Oropharynx Cancer;

De-ESCALATE, Determination of Cetuximab Versus Cisplatin Early and Late Toxicity Events in Human Papillomavirus+oropharyngeal Squamosus Cell Carcinoma; ECE, extracapsular extension; Gy, Gray; HPV,human papillomavirus; IC, induction chemotherapy; IMRT, intensitymodulated radiotherapy; N, number of patients; OPSSC,oropharyngeal squamosus cell carcinoma; PATHOS, post-operative Adjuvant Treatment for HPV-Positive Tumors; PR, partial response; PY, pack-years; RT,radiotherapy; RTOG,Radiation Therapy Oncology Group; TORS, transoral robotic surgery; TPF, docetaxel, cisplatin, fluorouracil, ECOG; EasternCooperative Oncology Group; CRT, chemoradiotherapy; PYH, pack/years

dysfunction ( $40 \%$ vs $89 \%$ ) or impaired nutrition ( $10 \%$ vs $44 \%$ ) (ref. ${ }^{31}$ ). However, among patients with good prognosis (non-smoking patients with less than T4 tumours and ipsilateral nodes smaller than $6 \mathrm{~cm}$ ) who achieved a complete primary site response to IC, the 2-year PFS rate was 96\% (ref. ${ }^{31}$ ). This supports the importance of careful patient selection for treatment deintensification approaches. The 15-Gy reduction in radiation dose seemed to improve measured swallowing outcomes and nutritional status ${ }^{32}$. Similarly, results of the phase II OPTIMA clinical trial indicate that patients with HPV-positive head and neck cancers can receive substantially lower radiation doses safely and effectively if they respond to IC initially. Sixtytwo patients received three cycles of IC (carboplatin and nab-paclitaxel), and those who responded well received one of two de-escalated treatment regimens: $50 \mathrm{~Gy}$ of RT alone (RT50 arm) for low-risk disease $(\leq \mathrm{T} 3, \leq \mathrm{N} 2 \mathrm{~B}$, $\leq 10$ pack-year smoking history), or 45 Gy of chemoradiation therapy (CRT45 arm) for high-risk disease (T4 or $\geq \mathrm{N} 2 \mathrm{C}$ or $>10$ pack-years). Patients without a favourable response received regular-dose CRT to 75 Gy (CRT75 arm). All patients also received de-escalated RT volumes limited to the first echelon of univoled nodes. All low-risk patients and 32 of the 34 (94\%) of the high-risk patients were progression-free at two years following treatment ${ }^{33}$. 2-year OS were $100 \%$ for low-risk patients and $97 \%$ for high-risk patients ${ }^{33}$. Side effects from de-escalated therapy were significantly improved compared to standard treatment. Rates of grade 3 or higher mucositis were $16 \%$ for RT50, 46\% for CRT45 and 60\% (ref. ${ }^{33}$ ) for CRT75. Based 
on these results, favourable response to IC appears to be a powerful biomarker for dose and volume CRT deescalation. Outstanding survival and high response to IC suggest that completion neck dissection may not be necessary. Further evaluation of induction-based de-escalation in large multicentre studies is justified. The Quarterback is an active phase III randomised, non-inferiority trial. A total of 365 patients with locally advanced HPV+OPC will be treated with 3 cycles induction chemotherapy (Docetaxel, Cisplatin, and 5-FU). Partial or complete responders are randomised to receive a reduced $(56 \mathrm{~Gy})$ or standard (70 Gy) dose RT with weekly carboplatin. Patients not meeting the response criteria are treated with standard dose chemoradiation (up to $70 \mathrm{~Gy}$ ). The primary endpoint is equivalent locoregional control and PFS at 3 years $^{34}$. Very preliminary outcomes based on 23 patients enrolled and 20 randomised were presented at the ASCO meeting in 2017, and the 2-year PFS were $87.5 \%$ for those patients receiving standard doses and $83.3 \%$ (ref. ${ }^{35}$ ) for those patients receiving dose deescalation. Toxicity and quality of life data were not included.

\section{Minimally invasive surgical techniques}

Concerns relating to CRT (including the development of metachronous radiation-induced sarcomas and the deleterious systemic effects of cytotoxic drugs) have brought surgery back into the spotlight as a primary treatment option for OPC. The last de-intensification treatment approach consists of incorporation of minimally invasive surgical techniques such as trans-oral robotic surgery (TORS). TORS for operable HPV+OPC is increasingly considered an alternative to CRT as a consequence of fast functional recovery and high effectiveness in terms of tumour control ${ }^{36-38}$. While minimally invasive surgery reduces morbidity, the treatment-related toxicity is still considerable, particularly in patients who receive adjuvant treatment with RT or CRT (in patients with pathologic evidence of extracapsular extension (ECE) or close/ positive margins in the primary resection specimen). For instance, one analysis showed a $0 \%$ rate of gastrostomy tube use in T1/T2 OPC patients treated with TORS alone, versus a $44.4 \%$ rate of gastrostomy tube use and a $22.2 \%$ rate of gastrostomy tube dependence 1 year after TORS in patients who required adjuvant therapy ${ }^{39}$. TORS, like most treatments, can have important treatment-related adverse effects. The most common and serious complication of TORS is postoperative haemorrhage, with an incidence rate ranging from 3 to $8 \%\left(\right.$ ref $\left.^{40}\right)$. This potentially fatal complication frequently requires a second surgical procedure to control the bleeding ${ }^{41,42}$. Moreover, TORS-based treatment is criticised because a large percentage (about $50 \%$ ) of patients will still receive adjuvant CRT or RT, despite the disease being sufficiently manageable with concomitant CRT only (for advanced-stage disease) or RT only (for early-stage disease) ) $^{43,44}$. Early-stage disease is amenable to single-modality treatment (surgery vs RT) with similar efficacy in terms of tumour control. However, as of now, it remains unclear which treatment provides better functional recovery ${ }^{45-47}$. The method for reducing the percentage of adjuvant treatment is selecting patients for TORS (e.g. without radiographic ECE) ( ref. $^{48,49}$ ). The ORATOR, phase II study, if successful, will provide a much-needed randomised comparison of the conventional strategy of primary RT vs the novel strategy of primary TORS. The trial is designed to provide a definitive quality of life comparison between the two arms ${ }^{50}$. This is currently in progress with an estimated completion date of June 2021. To further reduce morbidity after surgery, ongoing trials explore reducing the dose of adjuvant RT or eliminating adjuvant chemotherapy in patients with risk factors (ECE, positive surgical margins). There are three trials (PATHOS, ADEPT and ECOG 3311) currently underway evaluating the role of de-escalated CRT or observation following primary surgery (TORS combined with a staging neck dissection) for stage III/IV disease ${ }^{28}$. ECOG 3311 is a phase II trial that involves patients after a transoral resection and neck dissection. A major focus was appropriate patient selection. Thus, patients who had clinical or radiographic evidence of matted nodes, and those for whom transoral resection was anticipated to result in positive surgical margins, were not enrolled. Patients are separated into risk groups based on lymph node positivity, ECE, and positive surgical margins. The aim of the study is to determine if it is possible to avoid adverse side-effects of post-surgical radiation and chemotherapy in low-risk patients (negative surgical margins, zero to one node involved with no ECE) and if reduced-dose RT is effective. Primary endpoints included both the feasibility of a large multi-institutional TORS trial (which has now been demonstrated) and the 2-year PFS. Secondary outcomes included toxicity, swallowing function, patient-reported outcomes, and the risk group distribution of these surgeon-selected patients for inclusion ${ }^{51}$. The Adjuvant Deescalation, Extracapsular Spread, p16 Positive, Transoral (ADEPT) trial is a phase III randomised clinical trial, which studies the intensity of adjuvant therapy in patients who have had their disease removed surgically by a minimally invasive approach, and who have ECE. After surgery, patients are randomised to receive either radiation alone (60 Gy), or radiation and weekly cisplatin during therapy ${ }^{52}$. This trial also de-escalates adjuvant RT fields, wherein radiation is not delivered to the primary bed in patients with completely resected $\mathrm{T} 1$ or $\mathrm{T} 2$ disease. Retrospective analysis showed that locoregional control was not compromised and g-tube use was decreased when primary bed radiation was eliminated ${ }^{53}$. The primary endpoint of the trial examines the impact of transoral laser surgery followed by less intensive adjuvant treatment on swallowing function in patients with $\mathrm{HPV}+\mathrm{OPC}$, as well as the effect of this approach on locoregional control and survival $^{52}$. The PATHOS, phase II/III trial will investigate the benefit of CRT in the high-risk group. Patients with positive margins or ECE are randomised between RT 60 Gy with or without concomitant chemotherapy. The low risk group will have no adjuvant therapy as per standard treatment. The medium risk group will be randomised to receive either standard (60 Gy) or de escalated (50 Gy) postoperative RT $\left(\right.$ ref. ${ }^{54}$ ). These three studies should add 
to our understanding of the survival and functional outcomes that result from de escalation of adjuvant therapy in patients with high risk OPC.

\section{Prognostic factors in HPV-OPC}

HPV infection status is now well known as one of the most significant prognostic factors in $\mathrm{HPV}+\mathrm{OPC}$ patients, followed by smoking history (selecting a cutpoint of 10 pack-years), $\mathrm{N}$ category (for HPV-positive tumours), and T category (for HPV-negative tumours) $\left(\right.$ ref. $\left.^{55,56}\right)$. HPV+OPC patients have a substantially higher rate of OS, with up to $28 \%$ absolute reduction in risk of death compared to HPV-negative individuals ${ }^{57}$. However, there is a group of HPV-positive patients who have treatment failure, resulting in poor prognosis in real-world clinical practice. Distant failure is equivalent to that for HPV-negative disease, but may manifest later and in more unusual locations than lungs (i.e. skin, liver, and brain) $\left(\right.$ ref. $\left.^{58,59}\right)$. It is important to identify the ideal patient group for treatment deintensification and to define prognostic risk groups to avoid undertreating the poorer-risk subset in $\mathrm{HPV}+\mathrm{OPC}$.

Prognostic risk groups. The landmark RTOG 0129 study stratified 266 patients with OPC and led to the identification of low-, intermediate-, and high-risk groups of patients based on response to CRT. The low-risk group consists of patients with HPV+OPC and a less than 10 pack-year (PY) history of tobacco use or more than $10 \mathrm{PY}$ history and a single metastatic neck node. These patients had 3- and 8-year OS rates of $93 \%$ and $81 \%$ (ref. ${ }^{56,60}$ ), respectively, stimulating de-escalation treatment protocols. The intermediate-risk group consists of patients with $>10$ PY smoking history, or with multiple nodes and/or $>6$ $\mathrm{cm}$ nodal disease and 3-year OS significantly lower (71\%) (ref ${ }^{5,60}$ ). Patients with advanced T4 primaries, multiple lymph nodes, and smoking histories of more than 10 PYs have an increased risk of disease progression and death and should not be considered for de-escalation trials ${ }^{59}$.

Smoking. The negative impact of smoking on HPVpositive patient's prognosis has been shown by several authors. HPV status of the tumor was the major determinant followed by number of PY of tobacco smoking $(\leq 10 v s>10)\left(\right.$ ref. $\left.^{56}\right)$. Smoking patients with HPV-positive tumours represent a clinical challenge due to their intermediate prognosis and significantly worse RT outcome compared to HPV-positive patients with a history of no or less-heavy smoking ${ }^{61,62}$. Compared to p16-negative patients, p16-positive patients had significantly better PFS (28.9\% absolute increase at 10 years) and OS (32.1\% absolute increase at 10 years) (ref. ${ }^{63}$ ). Smoking negatively impacted outcome; in the p16-positive subgroup, smokers never had significantly better PFS than former/current smokers (24.2\% survival benefit at 10 years) (ref. $\left.{ }^{63}\right)$. The risks of death and cancer relapse significantly increased by $1 \%$ for each additional pack-year of tobacco smoking ${ }^{64}$. Therefore, clinicians should strongly encourage smoking cessation amongst all head and neck cancer patients. There are scarce data on the relationships between smoking during treatment and the incidence and severity of radiotherapy-related complications. Some studies have reported a negative impact of continued smoking on treatment tolerance and outcomes in patients with head and neck cancer ${ }^{65,66}$. However, the data from other studies do not confirm this hypothesis ${ }^{67}$.

Positive surgical margins and ECE. Historically, positive surgical margins and ECE are the two most important risk factors in stratification of patients with head and neck cancer into a high-risk group that profits from adjuvant concomitant cisplatin-based treatment or RT alone ${ }^{68,69}$. The definition of an adverse feature in the context of HPV is an area of active research. ECE is reported to occur in approximately $60 \%$ of patients with regional neck metastasis and further decreases the prognosis of head and neck cancer patients ${ }^{70,71}$. The prognostic significance of ECE in $\mathrm{HPV}+\mathrm{OPC}$ is a matter of debate. ECE does not have the same adverse prognostic significance in $\mathrm{HPV}+\mathrm{OPC}$ as compared to HPV-negative tumours ${ }^{72}$. The key consideration for all surgical access in oncology is resection of the primary tumour with sufficient margins without a high risk of causing long-term functional impairment. The safety margin is considered the main indicator of oncological radicality ${ }^{73}$. The impact of the surgical margins on the outcome of HPV+OPC patients remains equivocal. Some studies showed evidence that positive margins were associated with poor outcome in terms of disease-free survival and mortality, but some studies failed to show this impact $^{72,74,75}$. These findings raise questions regarding the additional benefit of postoperative CRT in this group. ECE and surgical margins remain a mysterious condition and much progress still needs to be made, both at the clinical and basic research levels. Clinical trials also use different definitions for negative margins and ECE. There are currently no standardised histological diagnostic criteria for ECE and positive surgical margins. This lack of standardisation calls for the introduction of internationally accepted reproducible criteria for its diagnosis ${ }^{49}$.

\section{CONCLUSION}

The oropharynx plays an essential role in swallowing and speech. Treatment modalities are heavily influenced by the aim of reducing the risk of functional disability where possible. Thinking of better prognosis in patients with $\mathrm{HPV}+\mathrm{OPC}$ urge us to assess whether through deintensification of a standard treatment it is possible to achieve the same level of effectiveness and minimise adverse side-effects in young patients in good clinical condition. Clinical studies focus on radiation dose reduction, and the option of replacing nephrotoxic cisplatin and promoting minimally-invasive surgery within the treatment algorithm is discussed. Recent results from two trials, RTOG 1016 and De-ESCALaTE, provided similar conclusions that concurrent systemic therapy is important in the management of $\mathrm{HPV}+\mathrm{OPC}$, and modification or elimination of systemic therapy will be problematic. The increasing incidence of HPV+OPC, which often presents with small primary tumours, has reinvigorated the debate 
surrounding whether surgery or radiation is the optimal single-modality treatment of early-stage OPC. Whether primary TORS followed by appropriate adjuvant treatment results in survival and functional outcomes equivalent to (or better than) standard CRT is a bigger question. The standard of care for the definitive non-operative management of cisplatin-eligible patients with advanced disease is CRT for a total dose of approximately 70 Gy with concurrent high-dose cisplatin. For patients undergoing initial surgical resection, adjuvant CRT with concurrent high-dose cisplatin is recommended for those with positive surgical margins and/or extranodal tumour extension.

Although the prognosis of $\mathrm{HPV}+\mathrm{OPC}$ is better than that of HPV-negative OPC, currently the treatment of these two entities is identical. Less-intense treatment is an option only in the setting of clinical trials. Patients with HPV+OPC should be offered clinical trial options whenever they are available. Furthermore, deintensification in an unselected population of patients with $\mathrm{HPV}+\mathrm{OPC}$ has proven short-sighted. Treatment de-escalation is potentially conceivable in a select population of patients with low-risk HPV+OPC. However, this population must be specifically defined with clinicopathologic factors, or personalised approaches to treatment using risk estimates from published nomograms must be developed.

\section{Search strategy and selection criteria}

Our research strategy was aimed at evaluating studies discussing the role of HPV as etiologic agent of oropharyngeal carcinoma, its epidemiology, treatment and prognosis. The search was performed as broadly and comprehensively as possible. Scientific articles from 1985 to 2019 were searched using the Medline/PubMed, Scopus and Web of Science databases and references from relevant articles using the terms "HPV", "oropharynx cancer", "epidemiology“, "prevalence“, "treatment", "de-intensification", "de-escalation", "radiotherapy", "chemotherapy", "prognosis". All searches were up to date as of July 2019. Publications from the last 10 years were preferred.

Author contributions: JD: manuscript writing, literature search; MB: manuscript writing, literature search; SK: literature search, critical review of the manuscript.

Conflict of interest statement: The authors state that there are no conflicts of interest regarding the publication of this article.

\section{REFERENCE}

1. Vigneswaran N, Williams MD. Epidemiological Trends in Head and Neck Cancer and Aids in Diagnosis. Oral Maxillofac Surg Clin North Am 2014;26(2):123-41.

2. Gillison ML, Chaturvedi AK, Anderson WF,Fakhry C. Epidemiology of human papillomavirus-positive head and neck squamous cell carcinoma. J Clin Oncol 2015;33(29):3235-42.

3. Chaturvedi AK, Engels EA, Pfeiffer RM, Hernandez BY, Xiao W, Kim E, Jiang B, Goodman MT, Sibug-Saber S, Cozen W, Liu L, Lynch ChF, Wentzensen N, Jordan RC, Altekruse S, Anderson WF, Rosenberg PS, Gillison ML. Human Papillomavirus and Rising Oropharyngeal
Cancer Incidence in the United States. J Clin Oncol 2011;29(32):4294301.

4. Taberna M, Mena M, Pavón MA, Alemany L, Gillison ML, Mesia R. Human papillomavirus-related oropharyngeal cancer. Ann Oncol 2017;28(10):2386-98.

5. StankoP, Kruzliak P, Labas P. Role of human papilloma virus infection and oral-genital contact in oral cancer ethiopathogenesis. Bratisl Lek Listy 2013;114(6):345-8.

6. Okami K. Clinical features and treatment strategy for HPV-related oropharyngeal cancer. Int J Clin Oncol 2016;21(5):827-35.

7. Durková J. HPV-pozitivity as a prognostic and predictive marker of oropharyngeal cancer. Farmakoterapia 2016;6(2):120-6.

8. Bonilla-Velez J, Mroz EA, Hammon RJ, Rocco JW. Impact of human papillomavirus on oropharyngeal cancer biology and response to therapy: implications for treatment. Otolaryngol Clin North Am 2013;46(4):521-43.

9. Arenz A, Ziemann F, Mayer C, Wittig A, Dreffke K, Preising S, Wagner S, Klussmann JP, Engenhart-Cabillic R, Wittekindt C. Increased radiosensitivity of HPV-positive head and neck cancer cell lines due to cell cycle dysregulation and induction of apoptosis. Strahlenther Onkol 2014;190(9):839-46.

10. Stephen JK, Divine G, Chen KM, Chitale D, Havard S, Worsham MJ. Significance of p16 in Site-specific HPV Positive and HPV Negative Head and Neck Squamous Cell Carcinoma. Cancer Clin Oncol 2013;2(1):51-61.

11. Brierley JD, Cospodarowicz MK, Wittekind C. TNM Classification of Malignant Tumours,8th edition. Union for International Cancer Control. Wiley Blackwell 2017.

12. Masterson L, Moualed D, Liu ZW, Howard JE, Dwivedi RC, Tysome JR, Benson R, Sterling JC, Sudhoff H, Jani P, Goon PK. De-escalation treatment protocols for human papillomavirus-associated oropharyngeal squamous cell carcinoma: a systematic review and metaanalysis of current clinical trials. Eur J Cancer 2014;50(15):2636-48.

13. Mallory M, Butler-Xu Y, Chen AM. Irradiation of HPV-associated oropharyngeal cancer: Is less really more? Oncotarget 2018;9(16):125467.

14. Kalyankrishna S, Grandis JR. Epidermal growth factor receptor biology in head and neck cancer. J Clin Oncol 2006;24(17):2666-72.

15. Young RJ, Rischin D, Fisher R, McArthur GA, Fox SB, Peters LJ, Corry J, Lim A, Waldeck K, Solomon B. Relationship between epidermal growth factor receptor status, p16(INK4A), and outcome in head and neck squamous cell carcinoma. Cancer Epidemiol Biomarkers Prev 2011;20(6):1230-7.

16. Taberna $M$, Torres $M$, Alejo $M$, Mena $M$, Tous $S$, Marquez $S$, Pavón MA, León X, García J, Guix M, Hijano R, Bonfill T, Aguilà A, Lozano A, Mesía R, Alemany L, Bravo LG. The Use of HPV16-E5, EGFR, and pEGFR as Prognostic Biomarkers for Oropharyngeal Cancer Patients. Front Oncol [serial on the Internet]. 2018 Dec [cited 2019 June 12]; 8:589. Available from: https://www.ncbi.nlm.nih.gov/pmc/articles/PMC6297752/

17. Bonner JA, Harari PM, Giralt J, Cohen RB, Jones CU, Sur RK, Raben D, Baselga J, Spencer SA, Zhu J, Youssoufian H, Rowinsky EK, Ang KK. Radiotherapy plus cetuximab for locoregionally advanced head and neck cancer: 5-year survival data from a phase 3 randomised trial, and relation between cetuximab-induced rash and survival. Lancet Oncol 2010;11(1):21-8.

18. Rosenthal DI, Harari PM, Giralt J, Bell D, Raben D, Liu J, Schulten J, Ang KK, Bonner JA. Association of human papillomavirus and p16 status with outcomes in the IMCL-9815 phase III registration trial for patients with locoregionally advanced oropharyngeal squamous cell carcinoma of the head and neck treated with radiotherapy with or without cetuximab. J Clin Oncol 2016;34(12):1300-8.

19. Gillison ML, Trotti AM, Harris J, Eisbruch A, Harari PM, Adelstein D, Sturgis EM, Burtness B, Ridge J, Ringash J, Galvin J, Yao M, Koyfman SA, Blakaj DM, Razaq MA, Colevas D, Beitler JJ, Jones ChU, Dunlap NE, Seaward SA, Spencer S, Galloway GJ, Phan J, Dignam JJ. Radiotherapy plus cetuximab or cisplatin in human papilloma virus-positive oropharyngeal cancer (NRG Oncology RTOG 1016): a randomised, multicentre,non-inferiority trial. Lancet 2019;393(10166):40-50.

20. Mehanna $H$, Robinson $M$, Hartley A, Kong A, Foran B, Fulton-Lieuw T, Dalby M, Mistry P, Sen M, O'Toole L, Al Booz H, Dyker K, Moleron R, Whitaker S, Brennan S, Cook A, Griffin M, Aynsley E, Rolles $M$, De Winton E, Chan A, Srinivasan D, Nixon, Grumett J, Leemans CR, Buter J, Henderson J, Harrington K, McConkey C, Gray A, Dunn 
J. Radiotherapy plus cisplatin or cetuximab in low-risk human papillomavirus-positive oropharyngeal cancer (De-ESCALaTE HPV): an open-label randomised controlled phase 3 trial. Lancet 2019; 393(10166):51-60.

21. www.clinicaltrial.gov, [cited 2019 June 15]. Available from: https:// clinicaltrials.gov/ct2/show/NCT01855451

22. National Comprehensive Cancer Network (NCCN). Guidelines Head and Neck Cancers, Version 1.2019 [cited 2019 June 15]. Available from: http://www.ncen.org

23. Gillison ML, Blumenschein G Jr, Fayette J, Guigay J, Colevas AD, Licitra L, Harrington KJ, Kasper S, Vokes EE, Even C, Worden F, Saba NF, Iglesias Docampo LC, Haddad R, Rordorf T, Kiyota N, Tahara M, Monga M, Lynch M, Ferris RL. CheckMate 141: 1-Year Update and Subgroup Analysis of Nivolumab as First-Line Therapy in Patients with Recurrent/Metastatic Head and Neck Cancer. Oncologist 2018;23(9):1079-82.

24. Chow LQM, Haddad R, Gupta S, Mahipal A, Mehra R, Tahara M, Berger R, Eder JP, Burtness B, Lee SH, Keam B, Kang H, Muro K, Weiss J, Geva R, Lin CC, Chung HC, Meister A, Dolled-Filhart M, Pathiraja K, Cheng JD, Seiwert TY. Antitumor activity of pembrolizumab in biomarkerunselected patients with recurrent and/or metastatic head and neck squamous cell carcinoma: results from the phase Ib KEYNOTE-012 expansion cohort. J Clin Oncol 2016;34(32):3838-45.

25. Partlová S, Bouček J, Kloudová K, Lukešová E, Zábrodský M, Grega M, Fučíková J, Truxová I, Tachezy R, Špíšek R, Fialová A. Distinct patterns of intratumoral immune cell infiltrates in patients with HPV-associated compared to non-virally induced head and neck squamous cell carcinoma. Oncoimmunology [serial on the Internet]. 2015 Jan [cited 2019 June 12]; 4(1). Available from: https://www. ncbi.nlm.nih.gov/pmc/articles/PMC4368144/

26. Balermpas $P$, Rödel $F$, Krause $M$, Linge $A$, Lohaus $F$, Baumann $M$, Tinhofer I, Budach V, Sak A, Stuschke M, Gkika E, Grosu AL, Abdollah A, Debus J, Stangl S, Ganswindt U, Belka C, Pigorsch S, Multhoff G, Combs SE, Welz S, Zips D, Lim SY, Rödel C, Fokas E. The PD-1/PD$\mathrm{L} 1$ axis and human papilloma virus in patients with head and neck cancer after adjuvant chemoradiotherapy: a multicentre study of the German cancer consortium radiation oncology group (DKTKROG). Int J Cancer 2017;141(3):594-603.

27. Duprez F, Madani I, De Potter B, Boterberg T, De Neve W. Systematic review of doseevolume correlates for structures related to late swallowing disturbances after radiotherapy for head and neck cancer. Dysphagia 2013;28(3):337-49.

28. Levendag $P C$, Teguh DN, Voet $P$, van der Est $H$, Noever I, de Kruijf WJ, Kolkman-Deurloo IK, Prevost JB, Poll J, Schmitz PI, Heijmen BJ. Dysphagia disorders in patients with cancer of the oropharynx are significantly affected by the radiation therapy dose to the superior and middle constrictor muscle: a dose-effect relationship. Radiother Oncol 2007;85:64-73.

29. Feng FY, Kim HM, Lyden TH, Haxer MJ, Feng M, Worden FP, Chepeha $\mathrm{DB}$, Eisbruch A. Intensity modulated radiotherapy of head and neck cancer aiming to reduce dysphagia: early dose-effect relationships for the swallowing structures. Int J Radiat Oncol Biol Phys 2007;68:1289-98.

30. Addison D,Seidelmann SB, Janjua SA, Emami H, Staziaki PV, Hallett TR, BA Bálint S, Lu MT, MD, Cambria RP, Hoffmann U, Chan AW, Wirth LJ, MD, Neilan TG. Human Papillomavirus Status and the Risk of Cerebrovascular Events Following Radiation Therapy for Head and Neck Cancer. J Am Heart Assoc 2017;6(9):1-9.

31. Marur S, Li S, Cmelak JA, Gillison ML, Zhao WJ, Ferris RJ, Westra WH, Gilbert J, Bauman JE, Wagner LI, Trevarthen DR, Balkrishna J, Murphy BA, Agrawal N, Colevas AD, Chung CH, Burtness B. E1308: Phase II Trial of Induction Chemotherapy Followed by Reduced-Dose Radiation and Weekly Cetuximab in Patients With HPV-Associated Resectable Squamous Cell Carcinoma of the Oropharynx- ECOG ACRIN Cancer Research Group. J Clin Oncol 2017;35(5):490-7.

32. Cmelak AJ, Flamand Y, Li S, Marur S, Murphy BA, Cella D. Assessment of established patient reported outcomes (PROs) instruments measuring toxicities and quality of life (QOL) for patients (pts) with head and neck cancer (HNC) treated on ECOG 1308 and 2399 studies. J Clin Oncol 2017;35(suppl):abstr 6074.

33. Seiwert TY, Foster CC, Blair EA, Karrison TG, Agrawal N, Melotek JM, Portugal L, Brisson RJ, Dekker A, Kochanny S, Gooi Z, Lingen MW, Villaflor VM, Ginat DT, Haraf DJ, Vokes EE. OPTIMA: a phase II dose and volume de-escalation trial for human papillomaviruspositive oropharyngeal cancer. Ann Oncol 2019;30(2):297-302.

34. www.clinicaltrials.gov [cited 2019 June 22]. Available from: https:// clinicaltrials.gov/ct2/show/NCT01706939

35. Rainey H, Roy E., Selkridge I, Misiukiewicz K, Gupta V, Bakst RL. Standard of care vs reduced-dose chemoradiation after induction chemotherapy in HPV+ oropharyngeal carcinoma patients. J Clin Oncol 2017;35(15):6069.

36. Morisod B, Simon C. A meta-analysis on survival of patients treated with transoral surgery versus radiotherapy for early-stage squamous cell carcinoma of the oropharynx. Head Neck 2016;38 Suppl 1:E2143-50.

37. Adelstein DJ, Ridge JA, Brizel DM, Holsinger FC, Haughey BH, O'Sullivan B, Genden EM, Beitler JJ, Weinstein GS, Quon $\mathrm{H}$, Chepeha DB, Ferris RL, Weber RS, Movsas B, Waldron J, Lowe V, Ramsey S, Manola J, Yueh B, Carey TE, Bekelman JE, Konski AA, Moore E, Forastiere A, Schuller DE, Lynn J, Ullmann CD. Transoral resection of pharyngeal cancer: summary of a National Cancer Institute Head and Neck Cancer Steering Committee Clinical Trials Planning Meeting, November 6-7, 2011, Arlington, Virginia. Head Neck 2012;34(12):1681-703.

38. Golusiński W. Functional Organ Preservation Surgery in Head and Neck Cancer: Transoral Robotic Surgery and Beyond. Front Oncol. [serial on the Internet]. 2019 Apr [cited 2019 June 18]. Available from: https://www.ncbi.nlm.nih.gov/pmc/articles/PMC6479210/

39. Al-khudari S, Bendix S, Lindholm J, Simmerman E, Hall F, Ghanem T. Gastrostomy Tube Use after Transoral Robotic Surgery for Oropharyngeal Cancer. ISRN Otolaryngol. 2013; [serial on the Internet]. 2013 Jul [cited 2019 June 18]. Available from: https://www. ncbi.nlm.nih.gov/pubmed/23936676

40. Chia SH, Gross ND, Richmon JD. Surgeon Experience and Complications with Transoral Robotic Surgery (TORS). Otolaryngol Neck Surg 2013;149(6):885-92.

41. Mandal R, Duvvuri U, Ferris RL, Kaffenberger TM, Choby GW, Kim S. Analysis of post-transoral robotic-assisted surgery hemorrhage: frequency, outcomes, and prevention. Head Neck 2016;Suppl 1:77682.

42. Zenga J, Suko J, Kallogjeri D, Pipkorn P, Nussenbaum B, Jackson RS. Postoperative hemorrhage and hospital revisit after transoral robotic hemorrhage surgery. Laryngoscope 2017;127(10):2287-92.

43. Adelstein DJ, Ridge JA, Brizel DM, Holsinger FC, Haughey BH, O'Sullivan B, Genden EM, Beitler JJ, Weinstein GS, Quon $\mathrm{H}$, Chepeha DB, Ferris RL, Weber RS, Movsas B, Waldron J, Lowe V, Ramsey S, Manola J, Yueh B, Carey TE, Bekelman JE, Konski AA, Moore E, Forastiere A, Schuller DE, Lynn J, Ullmann CD. Transoral resection of pharyngeal cancer: summary of a National Cancer Institute. Head Neck 2012;34(12):1681-703.

44. Gildener-Leapman N, Kim J, Abberbock S, Choby GW, Mandal R, Duvvuri U, Ferris RL, Kim S. Utility of up-front transoral robotic surgery in tailoring adjuvant therapy. Head Neck 2016;38(8):1201-7.

45. Razafindranaly V, Lallemant B, Aubry K, Moriniere S, Vergez S, Mones ED, Malard O, Ceruse P. Clinical outcomes with transoral robotic surgery for supraglottic squamous cell carcinoma: experience of a French evaluation cooperative subgroup of GETTEC. Head Neck 2016;38 Suppl 1:1097-101.

46. Morisod B, Simon C. Meta-analysis on survival of patients treated with transoral surgery versus radiotherapy for early-stage squamous cell carcinoma of the oropharynx. Head Neck 2016;38 Suppl 1:2143150.

47. Monnier Y, Simon C. Surgery Versus Radiotherapy for Early Oropharyngeal Tumors: a Never-Ending Debate.Curr Treat Options Oncol 2015;16(9):42.

48. Baskin RM, Boyce BJ, Amdur R, Mendenhall MW, Hitchcock K, Silver N,Dziegielewski PT. Transoral robotic surgery for oropharyngeal cancer: patient selection and special considerations. Cancer Manag Res. [serial on the Internet]. $2018 \mathrm{Apr}$ [cited 2019 June 18]; 10:[about 5 p.]. Available from: https://www.ncbi.nlm.nih.gov/pmc/articles/ PMC5916264/

49. Hararah MK, Stokes WA, Jones BL, Oweida A, Ding D, McDermott J, Goddard J, Karam SD. Nomogram for preoperative prediction of nodal extracapsular extension or positive surgical margins in oropharyngeal squamous cell carcinoma. Oral Oncol 2018;83:73-80.

50. Nichols AC, Yoo J, Hammond JA, Fung K, Winquist $E$, Read N Venkatesan V, MacNeil SD, Ernst DS, Kuruvilla S, Chen J, Corsten 
M, Odell M, Eapen L, Theurer J, Doyle PC, Wehrli B, Kwan K, Palma DA. Early-stage squamous cell carcinoma of the oropharynx: radiotherapy vs. trans-oral robotic surgery (ORATOR)-study protocol for a randomized phase II trial. BMC Cancer [serial on the Internet]. 2013 Mar [cited 2019 June 19]; 13:133. Available from: https://www.ncbi. nlm.nih.gov/pmc/articles/PMC3621077/

51. Li S, Ferris RL, Holsinger FC, Weinstein GS, Quon H, Mehra R, Garcia JJ, Chung ChH, Gillison ML, Wagner LI, Ringash J, Lewin JS, Mendez E, Ridge JA, Richmon J, Magnuson S, Bell RB, Smith RB, Thomas $G$, Burtness B. E3311 trial of transoral surgery for oropharynx cancer: Implementation of a novel surgeon credentialing and quality assurance process. J Clin Oncol 2016;34(suppl):abstr 6054.

52. www.clinicaltrials.gov [cited 2019 June 22]. Available from: https:// clinicaltrials.gov/ct2/show/NCT01687413

53. Sinha P, Pipkorn P, Thorstad WL, Gay HA, Haughey BH. Does elimination of planned postoperative radiation to the primary bed in p16positive, transorally-resected oropharyngeal carcinoma associate with poorer outcomes? Oral Oncol 2016;61:127-34.

54. Owadally W, Hurt Ch,Timmins H, Parsons M, Townsend S, Patterson J, Hutcheson K, Powell N, Beasley M, Palaniappan N, Robinson M, Jones TM, Evans M. PATHOS: a phase II/III trial of risk-stratified, reduced intensity adjuvant treatment in patients undergoing transora surgery for Human papillomavirus (HPV) positive oropharyngeal cancer. BMC Cancer. [serial on the Internet]. 2015 Aug [cited 2019 June 26]; 15: 602. Available from: https://www.ncbi.nlm.nih.gov/ pmc/articles/PMC4549836/

55. Fakhry C, Westra WH, Li S. Improved survival of patients with human papillomavirus-positive head and neck squamous cell carcinoma in a prospective clinical trial. J Natl Cancer Inst 2008;100(4):261-9.

56. Ang KK, Harris J, Wheeler R, Weber R, Rosenthal DI, NguyenTân PF, Westra WH, Chung CH, Jordan RC, Lu C, Kim H, Axelrod $\mathrm{R}$, Silverman CC, Redmond KP, Gillison ML.Human papillomavirus and survival of patients with oropharyngeal cancer. N Engl J Med 2010;363(1):24-35.

57. Ragin CC, Taioli E. Survival of squamous cell carcinoma of the head and neck in relation to human papillomavirus infection: review and meta-analysis. Int J Cancer 2007;121(8):1813-20.

58. Posner MR, Lorch JH, Goloubeva O, Tan M, Schumaker LM, Sarlis $\mathrm{NJ}$, Haddad RI, Cullen KJ. Survival and human papillomavirus in oropharynx cancer in TAX 324: a subset analysis from an international phase III trial. Ann Oncol 2011;22(5):1071-7.

59. O'Sullivan B, Huang SH, Siu LL, Waldron J, Zhao H, Perez-Ordonez B, Weinreb I, Kim J, Ringash J, Bayley A, Dawson LA, Hope A, Cho J, Irish J, Gilbert R, Gullane P, Hui A, Liu FF, Chen E, Xu W. Deintensification candidate subgroups in human papillomavirusrelated oropharyngeal cancer according to minimal risk of distant metastasis. J Clin Oncol 2013:31(5):543-50.

60. Fakhry C, Zhang Q, Gillison ML, Nguyen-Tân PF, Rosenthal DI, Weber RS, Lambert L, Trotti AM 3rd, Barrett WL, Thorstad WL, Yom SS, Wong SJ, Ridge JA, Rao SSD, Spencer S, Fortin A, Raben D, Harris J, Le QT. Validation of NRG oncology/RTOG-0129 risk groups for HPV-positive and HPV-negative oropharyngeal squamous cell cancer: Implications for risk-based therapeutic intensity trials. Cancer 2019;125(12):202738.

61. Chen AM, Chen LM, Vaughan A, Sreeraman R, Farwell DG, Luu Q, et al. Tobacco smoking during radiation therapy for head-and-neck cancer is associated with unfavorable outcome. Int J Radiat Oncol Biol Phys 2011;79(2):414-9.

62. Maxwell JH, Kumar B, Feng FY, Worden FP, Lee JS, Eisbruch A, Wolf GT, Prince ME, Moyer JS, Teknos TN, Chepeha DB, McHugh JB, Urba SG, Stoerker J, Walline HM, Kurnit DM, Cordell KG, Davis SJ, Ward PD, Bradford CR, Carey TE. Tobacco use in human papillomavirus- positive advanced oropharynx cancer patients related to increased risk of distant metastases and tumor recurrence. Clin Cancer Res 2010;16(4):1226-35.

63. Lassen P, Lacas B, Pignon JP, Trotti A, Zackrisson B, Zhang Q, Overgaard J, Blanchard P; MARCH Collaborative Group. Prognostic impact of HPV-associated p16-expression and smoking status on outcomes following radiotherapy for oropharyngeal cancer: The MARCH-HPV project. Radiother Oncol 2018;126(1):107-15.

64. Gillison ML, Zhang Q, Jordan R, Xiao W, Westra WH, Trotti A, Spencer $\mathrm{S}$, Harris J, Chung $\mathrm{CH}$, Ang KK. Tobacco smoking and increased risk of death and progression for patients with p16-positive and p16negative oropharyngeal cancer. J Clin Oncol 2012;30(17):2102-11.

65. Smith J, Nastasi D, Tso R,Vangaveti V, Renison B,Chilkur M. The effects of continued smoking in head and neck cancer patients treated with radiotherapy: A systematic review and meta-analysis. RadioTher Oncol 2019;135:51-7.

66. Chen AM, Chen LM, Vaughan A, Sreeraman R, Farwell DG, Luu Q, Lau DH, Stuart K, Purdy JA, Vijayakumar S. Tobacco smoking during radiation therapy for head-and-neck cancer is associated with unfavorable outcome. Int J Radiat Oncol Biol Phys 2011;79(2):414-9.

67. Szeszko B, Osowiecka K, Rucińska M, Wasilewska-Teśluk E, Gliński K Kępka K. Smoking during radiotherapy for head and neck cancer and acute mucosal reaction. Rep Pract Oncol Radiother 2015;20(4):299304.

68. Bernier J, Domenge C, Ozsahin M, Matuszewska K, Lefebvre JL, Greiner RH, Giralt J, Maingon P, Rolland F, Bolla M, Cognetti F, Bourhis J, Kirkpatrick A, van Glabbeke M; European Organization for Research and Treatment of Cancer Trial 22931. Postoperative irradiation with or without concomitant chemotherapy for locally advanced head and neck cancer. New Engl J Med 2004;350(19):1945-52.

69. Cooper JS, PajakTF, Forastiere AA, Jacobs J, Campbell BH, Saxman SB, Kish JA, Kim HE, Cmelak AJ, Rotman M, Machtay M, Ensley JF, Chao KS, Schultz CJ, Lee N, Fu KK; Radiation Therapy Oncology Group 9501/Intergroup.Postoperative concurrent radiotherapy and chemotherapy for high-risksquamous-cell carcinoma of the head and neck. New Engl J Med 2004;350(19):1937-44.

70. Johnson JT, Myers EN, Bedetti CD, Barnes EL, Schramm Jr VL, Thearle PB. Cervical lymph node metastases: incidence and implications of extracapsular carcinoma. Arch Otolaryngol 1985;111(8):534-7.

71. Grandi C, Alloisio M, Moglia D, Podrecca S, Sala L, Salvatori P, Molinari R. Prognostic significance of lymphatic spread in head and neck carcinomas: therapeutic implications. Head Neck Surg 1985;8(2):67-73.

72. Sinha P, Kallogjeri D, Gay H, Thorstad WL, Lewis Jr JS, Chernock R, Molinari R. High metastatic node number, not extracapsular spread or N-classification is a node-related prognosticator in transorallyresected, neck-dissected p16-positive oropharynx cancer. Oral Oncol 2015;51(5):514-20.

73. Tirelli G, Zacchigna S, Boscolo Nata F, Quatela E, Di Lenarda R, Piovesana $\mathrm{M}$. Will the mininvasive approach challenge the old paradigms in oral cancer surgery? Eur Arch Otorhinolaryngol 2017;274(3):1279-89.

74. An Y, Park HS, Kelly JR, Stahl JM, Yarbrough WG, Burtness BA, Contessa JN, Decker RH, Koshy M, Husain ZA. The prognostic value of extranodal extension in human papillomavirus-associated oropharyngeal squamous cell carcinoma. Cancer 2017;123(14):276272.

75. Iyer NG, Dogan S, Palmer F, Rahmati R, Nixon IJ, Lee N, Patel SG, Shah JP, Ganly I. Detailed analysis of clinicopathologic factors demonstrate distinct difference in outcome and prognostic factors between surgically treated HPV-positive and negative oropharyngeal cancer. Ann Surg Oncol 2015;22(13):4411-21. 